Temporary clips were reapplied after waiting for 10 minutes. Permanent clips were placed at the neck of the aneurysm and excision of the aneurysm wall was done in 7 minutes. No change in SSEP was observed at this time. Further intraoperative course was uneventful and the patient was extubated. The power in the left upper limb decreased to 4/5 in the postoperative period that recovered to baseline in 12 hours.

The reduced blood flow during temporary clipping can cause reversible neurological changes. However, if not dealt immediately, there can be irreversible damage. ${ }^{3}$ SSEPs can be used to monitor and identify early reversible cerebral damage to decrease the morbidity of the patients. To conclude, SSEPs monitoring must be considered in all the complex aneurysmal surgeries to limit the temporary clipping time and preventing postoperative neurological deficits.

\section{Conflict of Interest}

None declared.

\section{References}

1 Krayenbühl N, Erdem E, Oinas M, Krisht AF. Symptomatic and silent ischemia associated with microsurgical clipping of intracranial aneurysms: evaluation with diffusion-weighted MRI. Stroke 2009;40(1):129-133

2 Kashkoush AI, Jankowitz BT, Nguyen C, et al. Perioperative stroke after cerebral aneurysm clipping: risk factors and postoperative impact. J Clin Neurosci 2017;44:188-195

3 Kashkoush AI, Jankowitz BT, Gardner P, et al. Somatosensory evoked potentials during temporary arterial occlusion for intracranial aneurysm surgery: predictive value for perioperative stroke. World Neurosurg 2017;104:442-451

\title{
Acute Sialadenitis and Threatened Airway following Posterior Fossa Surgery
}

\author{
Ashutosh Kumar ${ }^{1} \quad$ Ajay P. Hrishi ${ }^{1}$ Neeraja Ajayan ${ }^{1}$ \\ ${ }^{1}$ Neuroanesthesia Division, Department of Anesthesiology, Sree \\ Chitra Tirunal Institute for Medical Sciences and Technology, \\ Trivandrum, Kerala, India
}

J Neuroanaesthesiol Crit Care 2021;8:224-226.

Anesthesia mumps (also known as acute sialadenitis) is a rare postoperative complication related to extreme rotation or flexion of the head during surgery. ${ }^{1}$ Acute sialadenitis causing acute airway obstruction and requiring emergent tracheostomy has not been reported in the past. We describe a case of acute submandibular and parotid sialadenitis causing acute respiratory distress after posterior fossa craniotomy for the right cerebellopontine $(\mathrm{CP})$ angle lesion. Informed consent has been obtained from the patient for the images in this article.

A 45-year-old female weighing $60 \mathrm{~kg}$ with no known comorbidities presented with vestibular schwannoma in the right $\mathrm{CP}$ cistern. The patient was posted for a right retrosigmoid suboccipital craniotomy and tumor excision in the left

\author{
Manikandan Sethuraman ${ }^{1}$
}

Address for correspondence Ajay P. Hrishi, MD, DM, MNAMS, MIMSA, Neuroanesthesia Division, Department of Anesthesiology, Sree Chitra Tirunal Institute for Medical Sciences and Technology, 4th Floor, C Block, Trivandrum 695011, Kerala, India (e-mail: drajay@sctimst.ac.in).

park bench position. In the operating room, the standard ASA (American Society of Anesthesiologists) monitors, such as electrocardiography (ECG), noninvasive blood pressure, and pulse oximetry $\left(\mathrm{SpO}_{2}\right)$, were initiated, and anesthesia was induced with propofol $2 \mathrm{mg} / \mathrm{kg}$, fentanyl $3 \mu \mathrm{g} / \mathrm{kg}$, and vecuronium $0.1 \mathrm{mg} / \mathrm{kg}$. The trachea was intubated with a $7.5-\mathrm{mm}$ cuffed PVC (polyvinyl chloride) endotracheal tube fixed on the left corner of the mouth to facilitate nerve monitoring of the right facial nerve, and a bite block was inserted. The patient was placed in the left park bench position, and the head was fixed in a Mayfield clamp. A two-finger width between the mandible and clavicle was confirmed. She was ventilated with oxygen and air, with $\mathrm{FiO}_{2}$ being 0.5 , and anesthesia was maintained with propofol-based total intravenous published online

September 17, 2020
DOI https://doi.org/

$10.1055 / \mathrm{s}-0040-1716424$

ISSN 2348-0548. (c) 2020. Indian Society of Neuroanaesthesiology and Critical Care.

This is an open access article published by Thieme under the terms of the Creative Commons Attribution-NonDerivative-NonCommercial-License, permitting copying and reproduction so long as the original work is given appropriate credit. Contents may not be used for commercial purposes, or adapted, remixed, transformed or built upon. (https://creativecommons.org/licenses/by-nc-nd/4.0/).

Thieme Medical and Scientific Publishers Pvt. Ltd. A-12, 2nd Floor, Sector 2, Noida-201301 UP, India 
anesthesia with Schneider model to target effect-site concentration of $3.5 \mu \mathrm{g} / \mathrm{kg}$ and infusion of fentanyl $1 \mu \mathrm{g} / \mathrm{kg} /$ hour and atracurium $0.5 \mathrm{mg} / \mathrm{kg} /$ hour. The surgery lasted for 7 hours, and the patient was hemodynamically stable. Postsurgery, when the patient regained consciousness as there was no facial edema, macroglossia, or new neurologic deficits, the patient's trachea was extubated.

Four hours later, the patient complained of respiratory distress. Upon inspection, the patient was found to have a swelling of the lateral aspect of the neck on the left and to have inspiratory stridor. Adrenaline nebulization was initiated; however, the respiratory distress progressed rapidly. On examination of the oral cavity, there was no macroglossia or pharyngeal edema, and on indirect laryngoscopy, the glottis and vocal cords could not be visualized. Hence, it was decided to reintubate the patient. Reintubation was attempted with a video laryngoscope after confirming the ability to mask ventilate, but the soft tissue edema precluded the larynx's visualization. Immediately, the surgeons on standby performed an emergency surgical tracheostomy, and the air-

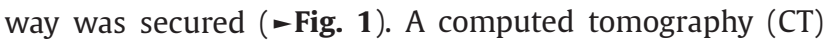
scan of the head and neck was performed, which showed a hypodense collection along the left parapharyngeal space, left side of pharyngeal mucosal space, left carotid space, and visceral space, extending till superior mediastinum. Besides, there was a marked displacement of the larynx and trachea towards the right side along with features suggestive of left parotitis and myositis of left masseter ( - Fig. 2). A neck fasciotomy was performed to relieve the pressure symptoms. The neck swelling subsided over the ensuing 4 to 5 days, and the patient was decannulated on the ninth postoperative day.

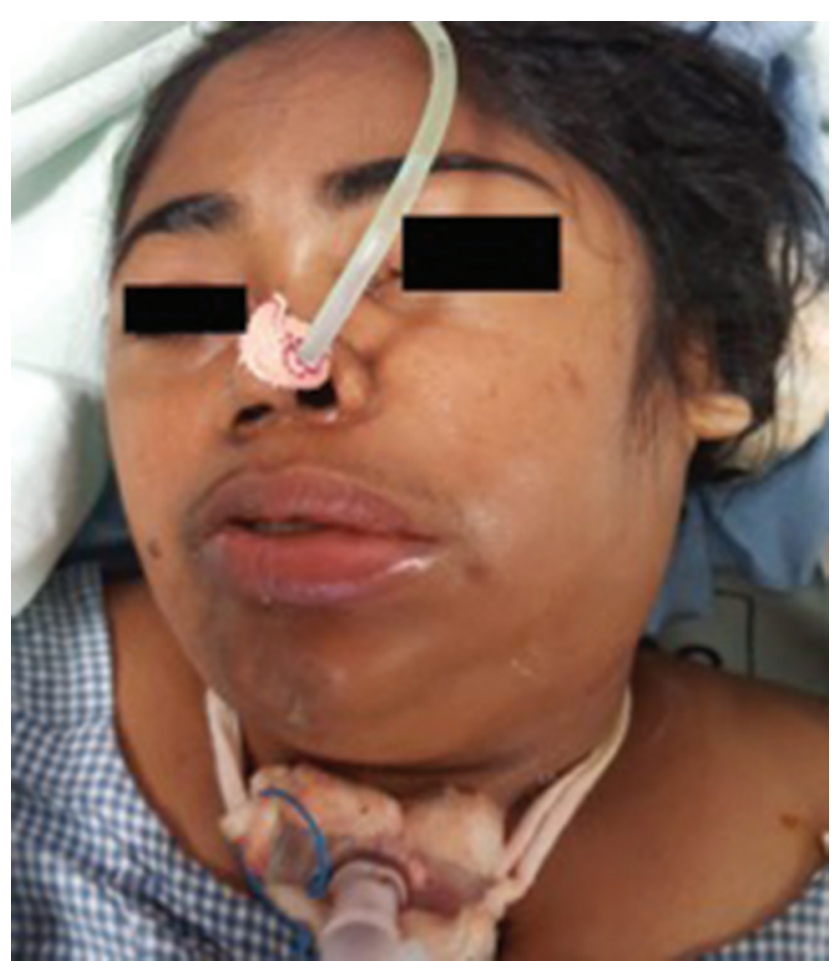

Fig. 1 Photograph showing severe swelling of face and neck with tracheostomy tube in situ.

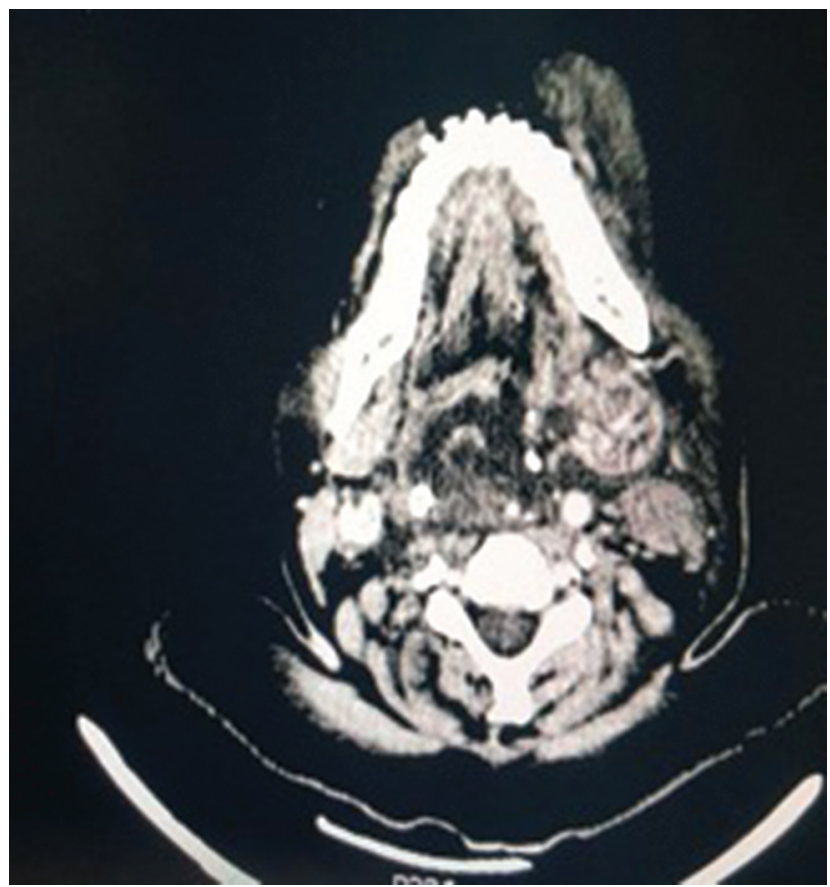

Fig. 2 Postoperative computed tomography scan showing the swelling of parotid and submandibular glands.

Acute postoperative sialadenitis after general anesthesia has an incidence of 5 in $3,000 .^{2}$ In patients undergoing surgery in retrosigmoid and far-lateral approaches, Kim et al reported the incidence of acute sialadenitis to be around $0.84 \%{ }^{2}$ In our case, acute sialadenitis caused acute respiratory distress requiring an emergent tracheostomy. The unique features of acute sialadenitis include a presentation with stridor and visible swelling in the neck and submandibular area, usually on the side contralateral to the side of surgery. ${ }^{1}$ Submandibular swelling is known to cause respiratory distress, which can be rapidly progressive, requiring emergency reintubation. ${ }^{3}$ The swelling of the soft tissue can also lead to brachial plexopathy. ${ }^{4}$ In our case, the patient did not develop any weakness of the upper limbs. Diagnosis is confirmed by CT scan or MRI (magnetic resonance imaging), demonstrating an enlarged submandibular gland and with edema of the surrounding soft tissue.

Risk factors include the retrograde flow of air through Stensen's orifice during straining and coughing during anesthesia, retention of secretions in the salivary duct, and dehydration. The use of drugs such as succinylcholine, atropine, and opioids has been reported to cause an increased incidence of postoperative sialadenitis. ${ }^{5}$ Other causative factors include salivary gland obstruction due to physical compression by lateral position, positions that rotate and flex the neck, compression by endotracheal tubes, mucosal lesions, edema, and sympathetic nervous system activation causing increased salivary viscosity leading to occlusion. ${ }^{5}$ Extreme head rotation leads to mechanical compression of the facial artery, which supplies the submandibular gland, leading to ischemia. In the postoperative period, as the head position returns to neutral, reperfusion injury of these tissues can occur. ${ }^{6}$ We placed the endotracheal tube on the contralateral side of surgery to 
facilitate facial EMG monitoring. This might have enhanced the compression of the submandibular gland and the encompassing tissues. The use of bite block throughout surgery may additionally be a predisposing factor. Therefore, it is recommended to secure the endotracheal tube on the ipsilateral side of the surgery to reduce tissue compression.

Acute sialadenitis following anesthesia is a rare complication that should be considered as one of the etiologies in patients presenting with acute postoperative respiratory distress, especially following surgeries in the park bench position. In a threatened airway scenario caused by sialadenitis, securing the airway could be difficult. Emergency tracheostomy is the next feasible option, which could be challenging due to the distorted anatomical landmarks owing to the neck swelling.

\section{Conflict of Interest}

None declared.

\section{References}

1 Uchino H, Motegi H, Kobayashi H, et al. Postoperative acute submandibular sialadenitis after neurosurgery: two case reports and a review of the literature. NMC Case Rep J 2015;3(1):1-4

2 Kim LJ, Klopfenstein JD, Feiz-Erfan I, Zubay GP, Spetzler RF. Postoperative acute sialadenitis after skull base surgery. Skull Base 2008;18(2):129-134

3 Singha SK, Chatterjee N. Postoperative sialadenitis following retromastoid suboccipital craniectomy for posterior fossa tumor. J Anesth 2009;23(4):591-593

4 Shimizu S, Sato K, Mabuchi I, et al. Brachial plexopathy due to massive swelling of the neck associated with craniotomy in the park bench position. Surg Neurol 2009;71(4):504-508

5 Hamaguchi T, Suzuki N, Kondo I. A case of anesthesia mumps that required postoperative re-intubation. JA Clin Rep 2018;4(1):22-25

6 Fujisawa Y, Aiyama S. Histochemical and chronological analysis of mouse submandibular gland parenchyma subjected to abrupt reperfusion. Histol Histopathol 2003;18(3):871-878

\title{
Using Smartphone Application to Guide the Angulation of Head End of Patient Bed
}

\author{
Summit D. Bloria Pallavi Bloria ${ }^{2}$ Rajeev Chauhan ${ }^{1}$
}

\author{
${ }^{1}$ Department of Anesthesia and Intensive Care, Postgraduate \\ Institute of Medical Education and Research, Chandigarh, India \\ 2Department of Anaesthesia, Government Medical College, Jammu, \\ Jammu and Kashmir, India
}

J Neuroanaesthesiol Crit Care 2021;8:226-227.

Traditionally, neurological patients have been nursed in intensive care units (ICUs) and hospital wards with head end elevated at 30 to 45 degrees. Also, in mechanically ventilated patients, elevation of head end of the patient bed at 45 degrees has been proven to significantly reduce the incidence of aspiration and ventilator-associated pneumonia (VAP). ${ }^{1}$ Indeed, ensuring head end elevation of at least 30 degrees is a part of almost all proposed VAP bundles that have documented lower VAP rates. ${ }^{2}$ However, it has been seen that the application of this simple intervention remains low. ${ }^{3}$ Reeve and Cook

\begin{abstract}
Address for correspondence Summit Dev Bloria, MD, DM, Department of Anesthesia and Intensive Care, Postgraduate Institute of Medical Education and Research, Chandigarh 160012, India (e-mail: summitbloria13@gmail.com).
\end{abstract}

found that majority of mechanically ventilated patients were kept with angle of the bed elevated less than 30 degrees. ${ }^{4}$

We believe that part of this low implementation is due to lack of knowledge, hospital practices, etc. While some ICU beds have a mechanical indicator (a small bead that moves along a scale on the side rail of the bed), in many ICUs and in hospital wards, the beds may not have any indicator of angle of head end elevation. Also, in the present coronavirus disease 2019 times with many newly established ICUs, ICU beds with angulation indicators may not be available. published online

October 16, 2020
DOI https://doi.org/

$10.1055 / \mathrm{s}-0040-1717831$

ISSN 2348-0548. (c) 2020. Indian Society of Neuroanaesthesiology and Critical Care.

This is an open access article published by Thieme under the terms of the Creative Commons Attribution-NonDerivative-NonCommercial-License, permitting copying and reproduction so long as the original work is given appropriate credit. Contents may not be used for commercial purposes, or adapted, remixed, transformed or built upon. (https://creativecommons.org/licenses/by-nc-nd/4.0/).

Thieme Medical and Scientific Publishers Pvt. Ltd. A-12, 2nd Floor, Sector 2, Noida-201301 UP, India 